\title{
Increasing Meal Frequency in Isoenergetic Conditions Does Not Affect Body Composition Change and Appetite During Weight Gain in Japanese Athletes
}

\author{
Motoko Taguchi and Akiko Hara \\ Waseda University \\ Suguru Torii \\ Waseda University
}

\author{
Hiroko Murata \\ Jumonji University and Waseda University
}

Takayuki Sako

Japan Women's University and Waseda University

\begin{abstract}
For athletes to gain body mass, especially muscle, an increase in energy consumption is necessary. To increase their energy intake, many athletes consume more meals, including supplementary meals or snacks. However, the influence of meal frequency on changes in body composition and appetite is unclear. The aim of this study was to determine the effect of meal frequency on changes in body composition and appetite during weight gain in athletes through a well-controlled dietary intervention. Ten male collegiate rowers with weight gain goals were included in this study. The subjects were randomly classified into two groups, and dietary intervention was implemented using a crossover method. During the intervention period, all subjects were provided identical meals aimed to provide a positive energy balance. The meals were consumed at a frequency of either three times (regular frequency) or six times (high frequency) a day. Body composition was measured using dual energy X-ray absorptiometry, and the visual analog scale was used for the evaluation of appetite. In both trials, body weight, fat-free mass, and fat mass significantly increased; however, an interaction $($ Trial $\times$ Time) was not observed. Visual analog scale did not vary between trials. Our data suggest that partitioning identical excess dietary intakes over three or six meals does not influence changes in body composition or appetite during weight gain in athletes.
\end{abstract}

Keywords: dietary intervention, energy balance, energy surplus, fat free mass, nutritional intake

Athletes often gain weight to build muscle mass and improve their performance. Weight gain results from deviations in the energy balance (EB; Tappy et al., 2013), and the EB must be positive in order to gain body weight (BW). The guidelines on sports nutrition for athletes (Macedonio \& Dunford, 2009; Rankin, 2002) recommended an energy increase of $500 \mathrm{kcal} /$ day for effective weight and muscle mass gain. However, these claims lack evidence, as no studies have targeted athletes in this context. Therefore, we focused on developing a dietary method for weight gain in athletes, while avoiding health risks. Our previous study performed a dietary intervention focused on EB in male athletes with weight gain goals. Athletes were fed meals targeting a positive EB of $1,000 \mathrm{kcal} /$ day above the individual total energy expenditure (TEE) for 12 weeks. According to the Dietary Reference Intakes for Japanese, the fat energy ratio was adjusted to $<30 \%$ during the intervention period. The fat-free mass (FFM) increased significantly without fat mass (FM) increase, and no health problems, such as abnormal glucose or lipid metabolism, ensued (Nagasawa et al., 2013).

In practice, however, when athletes consume large amounts of energy in three meals, increases in the volume of each meal can

Taguchi and Torii are with the Faculty of Sport Sciences, Waseda Institute of Sports Nutrition, Waseda University, Tokorozawa, Saitama, Japan. Hara, Murata, and Sako are with the Waseda Institute of Sports Nutrition, Waseda University, Tokorozawa, Saitama, Japan. Murata is also with the Department of Health and Nutrition, Jumonji University, Niiza, Saitama, Japan. Sako is also with Japan Women's University, Bunkyo-ku, Tokyo, Japan. Taguchi (mtaguchi@waseda.jp) is corresponding author. potentially cause gastrointestinal distress. Several athletes who participated in our previous study were psychologically stressed by a large single meal after exercise. Dallman (2010) indicated that people feel less hungry even toward comfort foods during a stressful period and reduce intake from the normal intake level. Few studies on the consumption of energy-balanced meals have performed longterm interventions (Munsters \& Saris, 2012; Smeets \& WesterterpPlantenga, 2008). Stote et al. (2007) performed a dietary intervention for 6 weeks to compare the effect of meal frequency (one vs. three meals) on body composition changes in sedentary subjects. One meal a day is not feasible for athletes, even if the meal contributes to BW maintenance. Studies targeting athletes have focused on meal frequency during the weight loss period (Deutz et al., 2000; Iwao et al., 1996), but few have studied athletes during weight gain. Thus, the effect of meal frequency on body composition changes and appetite during weight gain in athletes needs to be evaluated.

The aim of this study was to investigate the effect of meal frequency on changes in body composition and appetite during weight gain in athletes, building on our previous intervention research. We hypothesized that frequent meals would be more advantageous for ease of eating even if there is no difference in weight gain due to isoenergetic condition.

\section{Methods}

\section{Subjects}

Eleven healthy male lightweight rowers were recruited from a university rowing team with weight gain goals. One athlete dropped 
out during the intervention due to a personal reason; as such, ten athletes (age: $20 \pm 1$ years; height: $169.9 \pm 3.0 \mathrm{~cm}$; BW: $68.5 \pm$ $4.5 \mathrm{~kg}$; body fat percentage: $12.4 \pm 2.1 \%$; FFM: $60.0 \pm 3.2 \mathrm{~kg}$ ) were included. They participated in a regular training regimen, with a stable BW for over 1 month before the study. All subjects competed in the national intercollegiate games as oarsmen in the same rowing team, lived in the same boarding house, and shared similar lifestyles. Blood tests were performed before the study, confirming that the subjects had good nutritional and physical status (e.g., no iron or lipids abnormalities). The study aims, intervention, and measurement methods were fully explained to the subjects. Written informed consent was obtained prior to the study. This study was approved by the ethics committee review board of Japan Women's College of Physical Education for the use of human subjects in accordance with the Declaration of Helsinki.

\section{Study Design}

The study design is shown in Figure 1. To avoid bias due to individual differences among subjects, the athletes were randomly classified into two groups, and dietary intervention was implemented using a crossover method. We referred to the dietary intervention method used in our previous study (Nagasawa et al., 2013). TEE was measured before the study to determine the target energy intake and meal content during dietary intervention. During two trials for 8 weeks each, all subjects consumed identical meals, with meals consumed at a frequency of either three times a day (regular frequency) or six times a day (high frequency). Energy status, $\mathrm{BW}$, and appetite were monitored during the trials. A 5-week interval

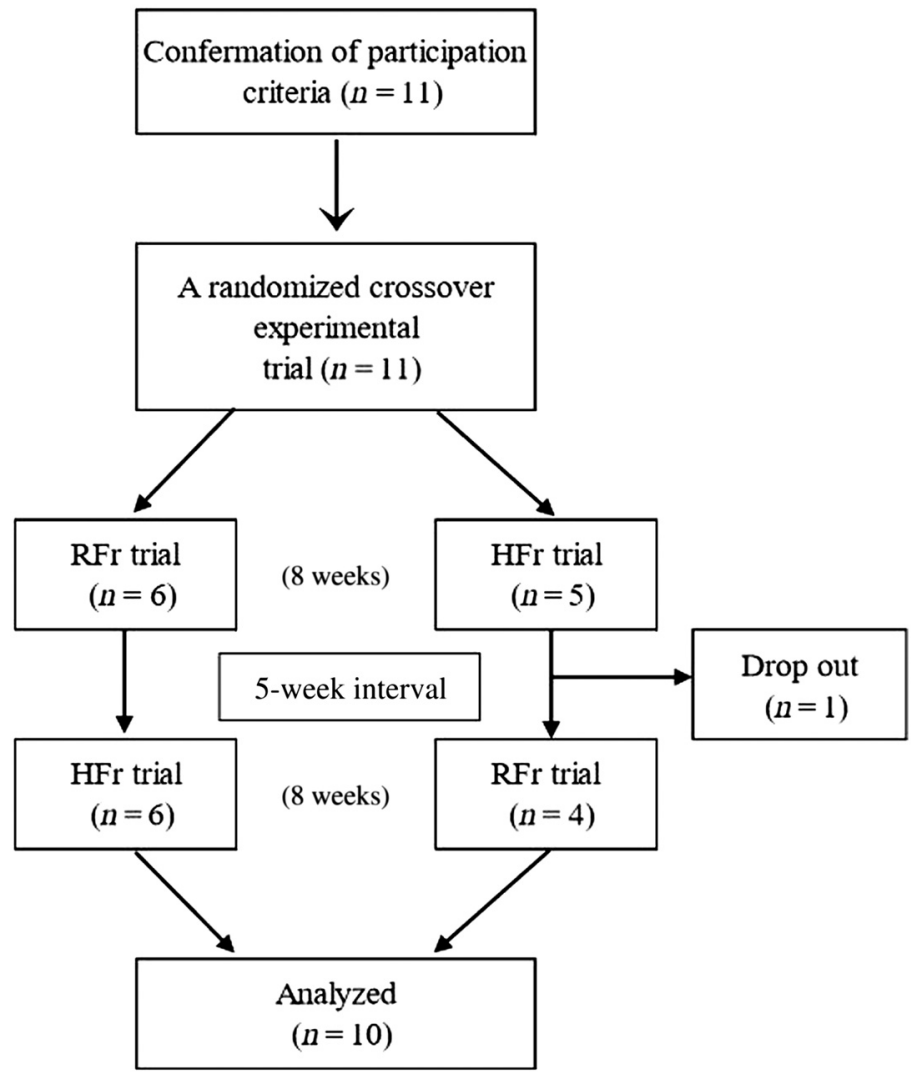

Figure 1 - Flow diagram of the consolidated standards of reporting trial. $\mathrm{HFr}=$ high frequency, six times a day; $\mathrm{RFr}=$ regular frequency, three times a day. period without any intervention was sandwiched between trials and BW changes with a normal diet were monitored. Body composition measurements were performed pre- and postintervention in each trial.

\section{Total Energy Expenditure}

Before the study, a multistage exercise tolerance test using a rowing ergometer (ConceptII; Concept Inc., White River Junction, VT) was conducted. The exercise was continued until exhaustion, and oxygen uptake and heart rate (HR) were continuously measured using an automatic expiration gas analyzer (AE 300S; Minato Medical Science Co., Ltd., Osaka, Japan) and an HR monitor (Polar S610; Polar Electro Co., Ltd., Kempele, Finland), respectively. A HR oxygen uptake relational formula was created for each individual subject. The subjects wore a HR monitor (Polar Electro Co.) for 1 month before the intervention, which was used to calculate energy expenditure during exercise. An accelerometer (Actimarker; Panasonic Corporation, Osaka, Japan) was used to determine the daily living energy expenditure. The subject's daily living and exercise energy expenditures were totaled to obtain the TEE of their regular training season (Ainslie et al., 2003).

\section{Total Energy Intake and EB}

The subjects were required to consume meals targeted at $20 \mathrm{kcal} / \mathrm{kg}$ BW of surplus energy from TEE for 8 weeks in both trials. Dietitians ensured the menus contained adequate nutrients. Meals were provided throughout the trials. The subjects were instructed to consume the entire meals and not use any supplements, and identical menus were used for both trials. Subjects were interviewed by dietitians once a week during the study to confirm compliance. Training time and meal timing during the intervention period were controlled, and where possible the meal timings were arranged at even time intervals between meals. Energy and nutrient intakes were calculated using nutrition software (Wellness 21; Top Business System Co., Okayama, Japan). Finally, EB was calculated as total energy intake minus TEE.

\section{Appetite}

Visual analog scale (VAS) was used to subjectively evaluate appetite (Oshima et al., 2017). The subjects were asked to record their degree of satiety before every meal during the trials, on a 100$\mathrm{mm}$ VAS ranging from very full to very hungry.

\section{BW and Composition}

The subjects were instructed to record their own BW every morning after voiding and before breakfast using a digital weighing scale (UC-321; A\&D Co., Ltd., Tokyo, Japan) with an accuracy of $0.05 \mathrm{~kg}$. Body composition was measured by dual energy X-ray absorptiometry (Delphi A, version 12.4:3, Fan beam, auto wholebody mode; Hologic Inc., Bedford, MA) in the morning fasted and rested after voiding at pre- and posttrials. All scans and analyzes were carried out by the experienced orthopedic surgeon who is the coauthor of this study (S. Torii). The mean coefficient of variations of FM and FFM were $<1 \%$.

\section{Statistical Analysis}

All data are presented as the mean $\pm S D$. Statistical analysis was performed using SPSS (version 26; IBM, Corp., Armonk, NY). A paired $t$ test was used to analyze the differences in the parameters 
within trials. A two-way repeated-measures analysis of variance was used to assess the presence of interactions (Trial $\times$ Time) in body composition change. Effect sizes were calculated based on Cohen's $d$ (Cohen, 1988). Statistical significance was set at $p<.05$.

\section{Results}

Energy status, nutritional intake levels, and EB were not significantly different between the trials (Tables 1 and 2). Changes in BW and body composition are shown in Table 3. BW was significantly gained in both trials, but no interactions (Time $\times$ Meals) were observed in any variables. There was no significant difference in appetite between the trials (Table 1).

\section{Discussion}

Meal frequency did not influence weight gain or body composition change, nor appetite when energy intake was controlled using a

Table 1 Energy Expenditure, Energy Intake Level, and Appetite of the Subjects During Intervention

\begin{tabular}{lccc}
\hline Variables & RFr & HFr & $\boldsymbol{p}$ value \\
\hline $\begin{array}{l}\text { Total energy expenditure } \\
\text { (kcal/day) }\end{array}$ & $3,849 \pm 348$ & $3,746 \pm 254$ & .393 \\
$\begin{array}{l}\text { Total energy intake } \\
\text { (kcal/day) }\end{array}$ & $5,244 \pm 133$ & $5,134 \pm 110$ & .070 \\
$\begin{array}{l}\text { Added energy intake } \\
\text { (kcal/kg BW) }\end{array}$ & $20.4 \pm 5.6$ & $19.9 \pm 4.4$ & .735 \\
$\begin{array}{l}\text { Energy balance (kcal/day) } \\
\text { Appetite (VAS) (mm) }\end{array}$ & $1,395 \pm 368$ & $1,388 \pm 300$ & .948 \\
\hline
\end{tabular}

Note. All data are reported as mean $\pm S D$; Paired $t$ test was used to compare trials. $\mathrm{BW}=$ body weight; $\mathrm{HFr}=$ high frequency; $\mathrm{RFr}=$ regular frequency; $\mathrm{VAS}=$ visual analog scale.

Table 2 Macronutrients and Micronutrients Intake of Two Meal Frequencies

\begin{tabular}{lccc}
\hline Variables & RFr & HFr & p value \\
\hline Protein $(\mathrm{g})$ & $185.0 \pm 4.9$ & $182.7 \pm 3.4$ & .221 \\
Protein $(\mathrm{g} / \mathrm{kg} \mathrm{BW})$ & $2.7 \pm 0.2$ & $2.6 \pm 0.1$ & .019 \\
Fat $(\mathrm{g})$ & $136.6 \pm 4.6$ & $133.0 \pm 3.7$ & .065 \\
Carbohydrate $(\mathrm{g})$ & $784.2 \pm 21.0$ & $768.8 \pm 17.7$ & .089 \\
Carbohydrate $(\mathrm{g} / \mathrm{kg} \mathrm{BW})$ & $11.5 \pm 0.8$ & $11.0 \pm 0.6$ & .011 \\
Calcium $(\mathrm{mg})$ & $1,214 \pm 67$ & $1,206 \pm 40$ & .754 \\
Iron $(\mathrm{mg})$ & $19.8 \pm 0.6$ & $19.6 \pm 0.5$ & .351 \\
Vitamin A ( $\mathrm{fg} \mathrm{RAE})$ & $1,124 \pm 44$ & $1,153 \pm 97$ & .439 \\
Vitamine $\mathrm{B}_{1}(\mathrm{mg})$ & $3.20 \pm 0.11$ & $3.17 \pm 0.08$ & .420 \\
Vitamine $\mathrm{B}_{2}(\mathrm{mg})$ & $2.98 \pm 0.10$ & $2.96 \pm 0.06$ & .653 \\
Vitamine C $(\mathrm{mg})$ & $233 \pm 13$ & $236 \pm 12$ & .444 \\
Dietary fiber $(\mathrm{g})$ & $26.1 \pm 1.0$ & $26.1 \pm 0.8$ & .971 \\
Energy ratio & & & \\
$\quad$ Protein $(\%)$ & $14.1 \pm 0.2$ & $14.2 \pm 0.1$ & .325 \\
$\quad$ Fat $(\%)$ & $23.4 \pm 0.4$ & $23.3 \pm 0.4$ & .324 \\
Carbohydrate $(\%)$ & $62.4 \pm 0.6$ & $62.5 \pm 0.4$ & .978 \\
\hline
\end{tabular}

Note. All data are reported as mean $\pm S D$; Paired $t$ test was used to compare trials. $\mathrm{BW}=$ body weight $\mathrm{HFr}=$ high frequency; $\mathrm{RAE}=$ retinol activity equivalents; $\mathrm{RFr}=$ regular frequency. metabolic feeding method. This study is the first to demonstrate the effect of meal frequency on body composition and appetite during weight gain in athletes via well-controlled dietary interventions.

\section{Energy Intake and Body Composition Change}

Previous studies (Munsters \& Saris, 2012; Smeets \& WesterterpPlantenga, 2008; Stote et al., 2007) on the relationship between meal frequency, body composition, and appetite have targeted sedentary or obese individuals. These studies were conducted using energy-balanced conditions for maintaining BW. Almost all these studies were short in duration, ranging from one to several days. Long-term dietary intervention studies have not been conducted, even on the general population. A very limited intervention study by Iwao et al. (1996) used a hypocaloric diet for weight loss in boxers. However, Schoenfeld et al. (2015) meta-analysis found a lack of significant impact of higher versus lower meal frequencies after sensitivity analysis on weight loss. Contrastingly, this study focused on the influence of meal frequency in athletes during weight gain. The diets were carefully monitored to maintain a positive $\mathrm{EB}$, and the intervention period was much longer than in previous studies. Moreover, despite the study being conducted under active field conditions, the timing and volume of meals and training during the two trials were regulated with the help of the coaches and the subjects. Therefore, the perspective of this study differs significantly from previous studies. A sports nutrition guideline (Dunford and Macedonio, 2017) indicates that increasing meal frequency, including snacks, is effective for increasing energy intake during weight gain period. In the field, when offering nutritional guidance to athletes with a high energy intake, the general advice from sports dietitians is to increase the number of meals or incorporate additional snacks. However, this guidance is empirical and without supporting evidence. Therefore, addressing this issue via well-controlled dietary intervention studies measuring the changes in body composition and appetite in athletes was imperative.

In our previous study (Nagasawa et al., 2013), athletes were provided all their meals and snacks for 12 weeks, aiming at a positive EB of 1,000 kcal/day (16-18 kcal/kg BW) and a fat energy ratio of $<30 \%$. As a result, BW and FFM increased by $3.8 \pm 1.3$ and $2.6 \pm 1.3 \mathrm{~kg}$, respectively, but no significant increase in FM was observed. The dietary intervention method in this study was based on our previous study. Forbes et al. (1986) found that total energy loading during overfeeding is related to the degree of weight gain. As the duration of one trial in this study was 8 weeks, shorter than that in the previous study, we decided to increase the surplus amount of energy slightly and set it around $20 \mathrm{kcal} / \mathrm{kg} \mathrm{BW}$ (Table 1 ). The results showed a significant increase in BW, FFM, and FM in both trials. Unlike our previous study, FM increased after the trials, resulting from higher energy intake. This result is similar to the study by Lammert et al. (2000), which demonstrated increased FM following a 1,000 kcal/day energy surplus in healthy, normalweight men, with no differences observed in FM change based on the fat and carbohydrate content of the diet. No interaction between trials was observed in body composition change (Table 3) due to an isoenergetic diet in this study.

The most interesting finding was that both trials resulted in a smaller weight gain than expected for higher energy loads. Based on Forbes's study (1986), which targeted normal young adults, the weight gain was estimated at about $6.3 \mathrm{~kg}$ in the case of an additional energy intake equivalent to that used in this study. Estimates using the National Institutes of Health weight planner 
Table 3 Change in Body Weight and Body Composition

\begin{tabular}{|c|c|c|c|c|c|c|c|c|c|}
\hline \multirow[b]{2}{*}{ Variables } & \multicolumn{3}{|c|}{ RFr } & \multicolumn{3}{|c|}{ HFr } & \multicolumn{3}{|c|}{$p$ value } \\
\hline & Pre & Post & Cohen's d & Pre & Post & Cohen's d & Time & Trial & Interaction \\
\hline BW (kg) & $68.48 \pm 4.64$ & $70.79 \pm 4.32$ & 0.51 & $69.93 \pm 4.37$ & $72.45 \pm 5.32$ & 0.52 & $<.001$ & .458 & .783 \\
\hline$\% \mathrm{BF}$ & $13.2 \pm 2.1$ & $14.4 \pm 2.7$ & 0.50 & $13.0 \pm 2.5$ & $14.2 \pm 2.7$ & 0.46 & $<.001$ & .826 & .889 \\
\hline $\mathrm{FM}(\mathrm{kg})$ & $9.11 \pm 1.88$ & $10.27 \pm 2.39$ & 0.55 & $9.10 \pm 2.10$ & $10.37 \pm 2.50$ & 0.52 & $<.001$ & .963 & .814 \\
\hline FFM (kg) & $59.36 \pm 3.32$ & $60.51 \pm 2.90$ & 0.35 & $60.82 \pm 3.31$ & $62.08 \pm 3.81$ & 0.37 & $<.001$ & .318 & .827 \\
\hline
\end{tabular}

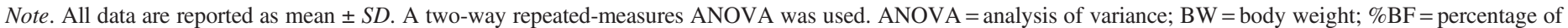
body fat; FM = fat mass; FFM = fat-free mass; $\mathrm{HFr}=$ high frequency; $\mathrm{RFr}=$ regular frequency.

(https://www.niddk.nih.gov/bwp), which helps adults set personal physical activity and calorie goals, showed that individuals require approximately $4,500 \mathrm{kcal} /$ day in order to obtain the mean weight gain of this study, that is, these comparisons showed that a larger amount of energy was needed to gain BW in this study. The biggest difference was the characteristics of the participants, as this study targeted athletes who routinely performed high-intensity training. A previous study (Campbell et al. 1994) showed that the mean energy intake required for BW maintenance increased by $15 \%$ with resistance training, even in older adults. In this study, high-intensity training was performed in the morning and afternoon 5 days a week and resistance training twice a week. To maximize muscle protein accretion with resistance exercise, daily protein intakes should be 1.6-2.2 g/kg BW (Stokes et al. 2018). Protein intakes were $2.7 \pm 0.2 \mathrm{~g} \cdot \mathrm{kg}^{-1} \cdot \mathrm{day}^{-1}$, and $2.6 \pm 0.1 \mathrm{~g} \cdot \mathrm{kg}^{-1} \cdot \mathrm{day}^{-1}$, respectively, in the trials. Energy expenditure has been observed to increase in accordance with protein intake (Bray et al. 2015). Diet-induced thermogenesis after protein intake is higher than that of both fat and carbohydrate (Tappy, 1996), which may have led to an increased energy consumption among the subjects (Stock, 1999), and dietinduced thermogenesis might be higher in athletes with high protein intake daily. The smaller weight gain should be associated with increased energy expenditure as Müller et al. (2016) stated. Silva et al. (2017) shows that body composition changes in athletes do not follow theoretical rules and predictions from nonathletic populations. This means that overfeeding in athletes is unlikely to use the same energy-conservation system as in ordinary adults, as more energy is needed to increase BW in athletes (Slater et al. 2019). As the impact of caloric overfeeding on muscle protein synthesis rates remains to be determined (Trommelen et al. 2019), further research is needed for its practical application in the field of sports.

\section{Meal Frequency and Appetite}

Although appetite is supposedly suppressed after strenuous training, there was no difference in appetite after high-intensity training in the previous study on athletes (Oshima et al., 2017). Training itself seems to have no effect on the appetite of athletes who undertake continuous training. Leidy and Campbell (2011) found that increasing meal frequency reduced the sensation of hunger and improved appetite control in sedentary subjects. Some studies have suggested that the sensation of satiety was maintained in groups who consumed a higher number of meals. In these studies, the subjects consumed an equivalent amount of energy and nutrients in meals that were consumed either twice or three times per day (Smeets \& Westerterp-Plantenga, 2008), three or six times per day (Stote et al., 2007), and once or five times per day (Speechly \& Buffenstein, 1999). Conversely, a study that compared three meals with fourteen meals per day found that the group that consumed a smaller number of meals had a higher level of satiety (Munsters \& Saris, 2012). This previous study suggested that it is easier to achieve a sense of satiety with larger energy intake in a single meal, which makes appetite control easier in normal-weight adults. However, in this study, a significant positive EB was maintained, unlike in other studies. The focus of our study was not appetite control, and the investigation used VAS to ascertain the degree of satiety from the perspective of ease of meal intake. Our results showed that there was no difference in the subjective assessment of appetite (satiety) between the two trials (Table 1). Comparing VAS within individuals, three subjects had higher values in regular frequency, four subjects had higher values in high frequency, and three subjects had similar values between trials, indicating that appetite was highly individualized. We could not prove our hypothesis that frequent meals are easier to eat. As VAS is a subjective ranking, it has the limitation of individual circumstances, thus requiring further research on the use of physiological indices. If there were no effects on changes in body composition, it would be acceptable to select a meal frequency depending on the ease with which an individual can eat the meals. Therefore, our findings could be applied to provide athletes nutritional support during periods of long-term weight gain.

\section{Limitations and Strengths}

This study has some limitations. First, the sample size was small with limited sporting events. To validate the findings related to meal frequency and changes in body composition, further research including measurement of resting energy expenditure will need to be performed using a variety of sports with larger sample size, especially for strength and power athletes. There is still a need to examine various feeding frequencies in hypercaloric conditions for the specific purpose of increasing FFM in programs involving progressive resistance training. Second, in intervention studies that use crossover methods, the protocol involves intervals between trials. We adopted a crossover design to compare changes within individuals undertaking similar physical activity. However, in practical scenarios, restoring the body composition before the second trial would be extremely difficult. This study was implemented while the athletes were undertaking actual activities in their daily life. Therefore, if a long interval were incorporated into the study, the training seasons would change, which would make maintaining fixed conditions impossible. Based on these factors, the interval period was set as the longest feasible period, namely 5 weeks, considering the athletes' training schedule.

To our knowledge, this study is the first to demonstrate the effect of meal frequency on body composition and appetite during weight gain in athletes using dietary intervention and high precision body composition assessments and builds on our previous 
intervention research. The protein intakes in this study met and exceeded intake levels likely to maximize FFM gain. This abundant intake is a design strength as it eliminates the possibility of the subjects not consuming enough total protein to legitimately test the independent effect of different meal frequencies. Factors, such as genetic factors, digestion and absorption capability, and metabolic changes, may contribute differences between individuals. Therefore, these factors must be carefully considered with respect to the relationship between energy loading, meal frequency, and weight control strategies in athletes.

\section{Conclusions}

Differences in meal frequency under isoenergetic conditions did not affect body composition changes or appetite during weight gain in athletes. To use these findings as a nutritional strategy for weight gain in the field, it is preferable to select meal frequencies based on individual's circumstances, taking into consideration factors such as individual differences and lifestyle environment, while regularly monitoring body composition.

\section{Acknowledgments}

This study was supported by the research foundations of Japan Women's College of Physical Education and Waseda University. The authors wish to thank all the subjects and their coaches who agreed to participate and implement our study at the boarding house. The authors also extend our gratitude to Dr. Melinda Manore for her valuable advice in the editing of this paper. This study was designed by M. Taguchi and A. Hara; data were collected and analyzed by M. Taguchi, A. Hara, H. Murata, T. Sako, and S. Torii; data interpretation and manuscript preparation were conducted by M. Taguchi and H. Murata. All authors approved the final version of this paper. The authors declare no conflict of interest.

\section{References}

Ainslie, P.N., Reylly, T., \& Westerterp, K.R. (2003). Estimating human energy expenditure: A review of techniques with particular reference to doubly labelled water. Sports Medicine, 33(9), 683698. PubMed ID: 12846591 doi:10.2165/00007256-20033309000004

Bray, G.A, Redman, L.M., de Jonge, L., Covington, J., Rood J, Brock, C., ... Smith, S.R. (2015). Effect of protein overfeeding on energy expenditure measured in a metabolic chamber. American Journal of Clinical Nutrition, 101(3), 496-505. PubMed ID: 25733634 doi:10. 3945/ajcn.114.091769

Campbell, W.W., Crim, M.C., Young, V.R., \& Evans, W.J. (1994). Increased energy requirements and changes in body composition with resistance training in older adults. American Journal of Clinical Nutrition, 60(2), 167-175. PubMed ID: 8030593 doi:10.1093/ajcn/ 60.2 .167

Cohen J. (1988). Statistical power analysis for the behavioral sciences. Hillsdale, NJ: L. Erlbaum Associates.

Dallman, M.F. (2010) Stress-induced obesity and the emotional nervous system. Trends Endocrinology and Metabolism, 21(3), 159-165. doi:10.1016/j.tem.2009.10.004

Deutz, R.C., Benardot, D., Martin, D.E., \& Cody, M.M. (2000). Relationship between energy deficits and body composition in elite female gymnasts and runners. Medicine \& Science in Sports \& Exercise, 32(3), 659-668. PubMed ID: 10731010 doi:10.1097/00005768200003000-00017
Dunford, M., \& Macedonio M.A. (2017). Weight management. In K. Karpinski \& C.A. Rosenbloom (Eds.), Sports nutrition: A handbook for professionals (6th ed., pp. 218-235). Chicago, USA: Academy of Nutrition and Dietetics.

Forbes, G.B., Brown, M.R., Welle, S.L., \& Lipinski, B.A. (1986). Deliberate overfeeding in women and men: Energy cost and composition of the weight gain. British Journal of Nutrition, 56(1), 1-9. PubMed ID: 3479191 doi:10.1079/BJN19860080

Iwao, S., Mori, K., \& Sato, Y. (1996). Effects of meal frequency on body composition during weight control in boxers. Scandinavian Journal of Medicine \& Science in Sports, 6(5), 265-272. PubMed ID: 8960647 doi:10.1111/j.1600-0838.1996.tb00469.x

Lammert, O., Grunnet, N., Faber, P., Bjprnsbo, S.K., Dich, J., Larsen, L.O., ... Quistorff, B. (2000). Effects of isoenergetic overfeeding of either carbohydrate or fat in young men. British Journal of Nutrition, 84(2), 233-245. PubMed ID: 11029975 doi:10.1017/S000711450000 1471

Leidy, H.J., \& Campbell, W.W. (2011). The effect of eating frequency on appetite control and food intake: Brief synopsis of controlled feeding studies. Journal of Nutrition, 141(1), 154-157. PubMed ID: 21123467 doi:10.3945/jn.109.114389

Macedonio, M.A., \& Dunford, M. (2009). The athlete's guide to making weight (pp. 153-155). Champaign, IL: Human Kinetics.

Müller, M.J., Enderle, J., \& Bosy-Westphal, A. (2016). Changes in energy expenditure with weight gain and weight loss in humans. Current Obesity Reports, 5(4), 413-423. doi:10.1007/s13679-0160237-4

Munsters M.J.M., \& Saris, W.H. (2012). Effects of meal frequency on metabolic profiles and substrate partitioning in lean healthy males. PLoS One, 7(6), e38632. PubMed ID: 22719910 doi:10.1371/journal. pone. 0038632

Nagasawa, T., Murata, H., Muraoka, S., Natsui, H., \& Taguchi M. (2013). Study of new approaches to increase the body weight of Japanese athletes. Journal of Japanese Society of Clinical Sports Medicine, 21(2), 422-430.

Oshima, S., Takehata, C., Sasahara, I., Lee, E., Akama, T., \& Taguchi, M. (2017). Changes in stress and appetite responses in male powertrained athletes during Intensive training camp. Nutrients, 9(8), 912. doi:10.3390/nu9080912

Rankin, J.W. (2002). Weight loss and gain in athletes. Current Sports Medicine Reports, 1(4), 208-213. PubMed ID: 12831697 doi:10. 1249/00149619-200208000-00004

Schoenfeld, B.J., Aragon, A.A., \& Krieger, J.W. (2015). Effects of meal frequency on weight loss and body composition: A metaanalysis. Nutrition Reviews, 73(2), 69-82. doi:10.1093/nutrit/ nuu017

Silva, A.M., Matias, C.N., Santos, D.A., Rocha, P.M., Minderico, C.S., ... Sardinha, L.B. (2017). Do dynamic fat and fat-free mass changes follow theoretical driven rules in athletes? Medicine \& Science in Sports \& Exercise, 49(10), 2086-2092. PubMed ID: 28542004 doi:10.1249/MSS.0000000000001332

Slater, G.J., Dieter, B.P., Marsh, D.J, Helms, E.R., Shaw, G., \& Iraki, J. (2019). Is an energy surplus required to maximize skeletal muscle hypertrophy associated with resistance training. Frontiers in Nutrition, 6, 131. PubMed ID: 31482093 doi:10.3389/fnut. 2019.00131

Smeets, A.J., \& Westerterp-Plantenga, M.S. (2008). Acute effects on metabolism and appetite profile of one meal difference in the lower range of meal frequency. British Journal of Nutrition, 99(6), 13161321. PubMed ID: 18053311 doi:10.1017/S0007114507877646

Speechly, D.P., and Buffenstein, R. (1999). Greater appetite control associated with an increased frequency of eating in lean males. 
Appetite, 33(3), 285-297. PubMed ID: 10625522 doi:10.1006/appe. 1999.0265

Stock, M.J. (1999). Gluttony and thermogenesis revisited. International Journal of Obesity, 23(11), 1105-1117. PubMed ID: 10578199 doi:10.1038/sj.ijo.0801108

Stokes, T., Hector, A.J., Morton, R.W., McGlory C., \& Phillips, S.M. (2018). Recent perspectives regarding the role of dietary protein for the promotion of muscle hypertrophy with resistance exercise training. Nutrients, 10, 180. doi:10.3390/nu10020180

Stote, K.S., Baer, D.J., Spears, K., Paul, D.R., Harris, G.K., Rumpler, W.V., . . Mattson, M.P. (2007). A controlled trial of reduced meal frequency without caloric restriction in healthy, normal-weight, middle-aged adults. American Journal of Clinical Nutrition, 85(4), 981-988. PubMed ID: 17413096 doi:10.1093/ajcn/85.4.981

Tappy, L. (1996). Thermic effect of food and sympathetic nervous system activity in humans. Reproduction Nutrition Development, 36(4), 391-397. doi:10.1051/rnd:19960405

Tappy, L., Binnert, C., \& Schneiter, P.H. (2013). Energy expenditure, physical activity and body-weight control. Proceedings of the Nutrition Society, 62(3), 663-666. doi:10.1079/PNS2003280

Trommelen, J., Betz, M.W., \& van Loon, L.J.C. (2019). The muscle protein synthetic response to meal ingestion following resistance-type exercise. Sports Medicine, 49(2), 185-197. PubMed ID: 30659499 doi:10.1007/s40279-019-01053-5 